\title{
Laure Katsaros, Goncourt's Dream. Night Terrors in La fille Elisa
}

\section{Maria Emanuela Raffi}

\section{(2) OpenEdition}

1 Journals

\section{Edizione digitale}

URL: https://journals.openedition.org/studifrancesi/3171

DOI: 10.4000/studifrancesi.3171

ISSN: 2421-5856

\section{Editore}

Rosenberg \& Sellier

\section{Edizione cartacea}

Data di pubblicazione: 1 juillet 2013

Paginazione: 480

ISSN: 0039-2944

\section{Notizia bibliografica digitale}

Maria Emanuela Raffi, «Laure Katsaros, Goncourt's Dream. Night Terrors in La fille Elisa», Studi Francesi [Online], 170 (LVII | II) | 2013, online dal 30 novembre 2015, consultato il 02 février 2023. URL: http:// journals.openedition.org/studifrancesi/3171 ; DOI: https://doi.org/10.4000/studifrancesi.3171

Questo documento è stato generato automaticamente il 2 février 2023.

\section{(c) (i) (9)}

Creative Commons - Attribuzione - Non commerciale - Non opere derivate 4.0 Internazionale - CC BYNC-ND 4.0

https://creativecommons.org/licenses/by-nc-nd/4.0/ 


\title{
Laure Katsaros, Goncourt's Dream. Night Terrors in La fille Elisa
}

\author{
Maria Emanuela Raffi
}




\section{NOTIZIA}

LAURE KATSAROS, Goncourt's Dream. Night Terrors in La fille Elisa, «French Forum», 2011,

2-3, pp. 61-77.

Il forte legame tematico fra un sogno di Baudelaire descritto per lettera all'amico Asselineau nel 1856, il sogno di Edmond de Goncourt vent'anni dopo da cui è scaturito il racconto La Fille Elisa e la lettera spedita dal giovane Huysmans a Edmond due giorni prima a proposito del suo racconto Marthe histoire d'une fille, costituisce il punto di partenza dell'analisi di Laure Katsaros. La pornografia, reale o presunta, il bordello/ prigione, la figura della prostituta sono gli elementi comuni dei tre testi, ma Edmond de Goncourt ha utilizzato per il suo racconto anche fonti meno letterarie, costituite da articoli della « Gazette des Tribunaux» o dagli studi sull'isteria, soprattutto per quanto riguarda l'omicidio compiuto dalla protagonista. La Fille Elisa illustra infatti un percorso perfettamente naturalista di degradazione, ma l'aspetto che l'A. vuole mettere particolarmente in luce è la corrispondenza fra l'isteria della protagonista, la sua profonda alienazione, e i sintomi dello stesso disagio che il narratore riconosce in se stesso. Certo, le motivazioni addotte da Edmond de Goncourt sono diverse e nella «préface» viene sottolineato il valore di denuncia politica del racconto, che vuole mostrare "the horrendous effects of the penal 'code of silence'», secondo il quale le prigioniere venivano isolate e private di ogni comunicazione verbale. Purtroppo lo stesso successo di La fille Elisa e i suoi rifacimenti in chiave pornografica hanno messo in ombra gli intenti più scientifici, medici e sociali, del racconto e le sue proiezioni autobiografiche, che l'A. sottolinea mostrando come «La Fille Elisa epitomizes the terrors inherent in the modern writer's condition» e in particolare quelli di Edmond de Goncourt. 